1 Doutora e mestre em Literatura pela Universidade de Brasilia (UnB). Possui Graduação em LetrasPortuguês. Professora do Curso Superior de LetrasPortuguês do Instituto Federal de Brasilia (IFB). http://orcid.org/0000-0001-8362-1416

E-mail: julianamantovani@gmail.com

Recebido em: 13/2/2019. Aprovado em: 27/5/2019.

Endereço:

Stituto Federal de Brasilia.

São Sebastião)

71697040 - Brasilia, DF - Brasil

Telefone: (61) 21938134

\section{Ilustração e complementariedade fotoliterária: o caso de Nadja, de André Breton}

\author{
Illustration and photoliterary complementarity: the case of Nadja, by André Breton
}

Juliana Estanislau de Ataíde Mantovani ${ }^{1}$

Instituto Federal de Brasilia, Brasilia, DF, Brasil.

\section{RESUMO}

Este artigo se propõe a descrever e a analisar as relações fotoliterárias presentes em Nadja (1928), primeira narrativa em prosa de André Breton, bem como os efeitos dos sentidos gerados no todo da obra. Em nossa discussão, nos fundamentaremos nos conceitos basilares da Fotoliteratura (MONTIER, 2008; 2015) e faremos a análise pontual desse livro, com ênfase em alguns excertos textuais e em algumas imagens fotográficas inseridas na obra bretoniana. Nessa perspectiva, refletiremos também sobre o potencial conotativo da fotografia e, por fim, objetivaremos - a partir de tais investigações - a compreender as interações e as interferências estabelecidas entre o texto e a imagem, com a finalidade de defender a existência nessa obra de uma forma de ilustração em complementariedade.

Palavras-chave: Literatura. Fotografia. Ilustração em complementariedade. Nadja.

\section{ABSTRACT}

This article proposes to describe and to analyze the photoliterary relations present in Nadja (1928), André Breton's first prose narrative, as well as to analyze the effects of the senses generated in the whole of the work. In our discussion, we will base ourselves on the basic concepts of Photoliterary (MONTIER, 2008 and 2015) and we will analyze this book, with emphasis on some textual excerpts and on some photographic images inserted in Breton's work. From this perspective, we will also reflect on the connotative potential of photography and, finally, we will intend - from such investigations - to understand the interactions and the interferences established between the text and the image, in order to defend the existence in this work of a form of illustration in complementarity.

Keywords: Literature. Photography. Illustration in complementarity. Nadja. 


\section{Introdução}

$\mathrm{A}^{\mathrm{n}}$

partir de reflexões suscitadas por uma leitura interartística e sobretudo fotoliterária, bem como partindo de certas evidências que poderão ser demonstradas, este artigo se propõe a analisar as relações entre texto e imagem em Nadja (1928), de André Breton. Dessa forma, impelidos a refutar a ideia das ilustrações como redundantes, duplicatas do sentido do texto, nos concentraremos nas informações que podemos extrair do texto literário e apresentaremos o modo de inserção das fotografias nessa obra para destacar a sua ligação com o texto. Por fim, prosseguiremos com uma leitura fotoliterária que apontará para a complementariedade texto-imagem.

Para desenvolver tal percurso, assumimos a necessidade de recorrer aos estudos fotoliterários, fundamentando-nos nos textos basilares apresentados nas organizações de Jean-Pierre Montier, Littérature et photographie (2008) e Transactions photolittéraires (2015).

Nessa perspectiva, é importante frisar que o conceito Fotoliteratura designa a totalidade de conjunções que desde os anos 1840 ligam "a produção literária com a imagem fotográfica, os processos de fabricação específicos que a caracterizam e os valores (semióticos, estéticos, etc.) que ela infere"2 (MONTIER, 2015, p. 20, tradução nossa). Trata-se, por conseguinte, materialmente das produções ilustradas por fotografia, mas são também englobadas as obras que surgem a partir de imagens fotográficas ou aquelas nas quais os procedimentos e as noções associadas à fotografia, ideia de "revelação", retórica que envolve o negativo/positivo ou ainda descrições que se assemelhem a fotografias, desempenham um papel estrutural.

É nesse terreno, então, que situamos o nosso objeto de estudo: a primeira narrativa bretoniana, Nadja, uma prosa surrealista que mescla com equilíbrio quarenta e oito fotografias a um texto híbrido, marcado de eventos imprevisíveis e ancorado sob tons ao mesmo tempo ensaísticos e autobiográficos.

Optamos por apresentar uma tradução nossa, nesse e em outros casos em que não dispomos ainda de tradução em português das obras destacadas. Do original: la production littéraire avec l'image photographique, les processus de fabrication spécifiques qui la caractérisent et les valeurs (sémiotiques, esthétiques, etc.) qu'elle infère.

\section{Revendo o estatuto e o valor da ilustração}

Compreendida tal noção, mas antes de adentrarmos às fotografias de Nadja e as suas relações com o texto literário, gostaríamos de fazer um parênteses necessário acerca do estatuto da ilustração nas obras literárias. A singular relação de trocas texto-imagem nos livros ilustrados parece exigir uma postura crítica menos encerrada na supremacia do texto sobre a imagem e mais afeita à premissa das interferências mútuas. Notamos que, em geral, é em uma relação unilateral e hierárquica de dependência da imagem que tal interação é normalmente considerada, em uma tendência de ver a ilustração como um duplicata irrelevante sem levar em conta os hiatos intrínsecos dessa dinâmica de interação verbovisual, do que decorre a sua depreciação ou seu desmerecimento e apagamento nos estudos do cânone literário.

No seu artigo "A 'história da cegonha, de Karen Blixen, e a noção de ilustração"3 (2012), Hans Lund evoca as três funções que consensualmente são outorga das à ilustração: adornar, traduzir ou explicar um texto. Para além dessas possibilidades, no entanto, Lund introduz uma quarta, em que "o texto verbal se alterna com a representação visual, isto é, em certos pontos deixa de descrever para que a imagem o faça" (LUND, 2012, p. 171), definindo o seu conceito como "ilustração antifônica". Os exemplos dessa forma de ilustração são apresentados pelo autor a partir das obras de Sterne, Thackeray e Auster, que

não reforçam, elucidam, ornamentam nem interpretam o texto. Também não fazem referência a ele, não tecem comentários sobre ele, nem o 'duplicam'. Não são equivalentes visuais do texto. Nem são uma tradução visual dele. Em vez disso, desempenham a tarefa de criar sentido enquanto a narrativa textual faz uma pausa. Por um momento, o texto verbal se abstém do papel de descrever e o deixa para a imagem (LUND, 2012, p. 179).

Reconhecemos, todavia, que mesmo nos casos em que a ilustração atua como adorno, explicação ou tradução de um texto, suas especificidades não são jamais ignoradas na leitura do todo da obra. No primeiro caso, as ilustrações que

Conforme tradução de Thaïs Flores Nogueira Diniz e Glória Maria Guiné de Mello, publicada no livro Intermidialidade e Estudos Interartes: desafios da arte contemporânea 2 (2012). 
adornam geram também "pausas no processo de leitura e, ao mesmo tempo, homenageiam o texto, influenciando assim indiretamente a atitude do leitor em relação ao que está lendo" (LUND, 2012, p. 175). No segundo, por sua vez, a imagem pode buscar confirmar e elucidar o que está expresso verbalmente, mas não pode ser um substituto completo, um equivalente do texto, justamente porque se configura sob um outro sistema de signos. Do mesmo modo ocorre no terceiro caso, por fim, em que mais uma vez a transferência do sentido do texto para as imagens permanece impossível, tendo em vista que mesmo a tradução no interior do sistema linguístico pressupõe uma distância, um hiato que "entre uma descrição verbal e sua representação visual será, é claro, mais amplo e de um tipo bem diferente" (LUND, 2012, p. 176). É preciso, portanto, rever a atitude crítica de reduzir as ilustrações a "escravas do texto".

O ilustrador é antes de tudo um intérprete e "suas interpretações necessariamente irão limitar ou reduzir o conteúdo do texto polissêmico". Por outro lado, não sendo capaz de expressar todos os significados do texto, ele precisa sempre fazer escolhas que ocasionam acréscimos no texto: "sua representação, muito provavelmente, oferecerá informações enraizadas no mundo visual, informações estas que o texto não consegue mediar em palavras" (LUND, 2012, p. 177).

Mesmo diante dos processos complexos de interação, Hans Lund destaca precisamente a percepção de W. J. T. Mitchell acerca de uma "tendência natural de reduzir ilustrações a traduções visuais do texto verbal". Em contrapartida a essa inclinação, Mitchell (1978 apud LUND, 2012)recomenda o tratamento das figuras "em seus próprios termos, como tipos distintos de sistemas de significados, contendo formas não verbais, alusões e implicações estilísticas" e defende que a unidade de um texto ilustrado é "a dinâmica construída sobre a interação do texto e do desenho como elementos independentes ou contrários" (MITCHELL, 1978 apud LUND, 2012, p. 179). Nessa interação, o que se opera no texto ilustrado é um "casamento de iguais".

Em nossa interpretação, portanto, a ilustração, seja ela categorizada como adorno, tradução, explicação ou complemento de um texto, estando em relação de "supremacia" ou de "inferioridade", em diálogo ou em complementariedade, sempre interfere e modifica a percepção de um texto literário e, como afirma Judith L. Fischer, o leitor não poderá buscar as ilustrações para confirmação de uma história, "porque elas tanto fixam imagens quanto evocam interpretações além daquelas contidas no texto" (1995 apud LUND, 2012, p. 179).
Ainda que as ilustrações visem a duplicar ou reiterar os sentidos do texto, os seus acréscimos e alterações são inevitáveis. Toda ilustração é uma interação texto-imagem; a qualidade estética ou o resultado de tais interações para a economia da obra literária não estão em jogo nessa afirmação e, por conseguinte, não se justifica nessa perspectiva a postura de desmerecer o valor das ilustrações como atributos de textos literários "menores" ou como um aspecto do livro a ser ignorado. Acreditamos ainda que essa conduta de desprezo pelas ilustrações provavelmente é o que nos impediu muitas vezes nos estudos literários de fazer análises mais coerentes de obras ilustradas. Percebemos, aliás, que os estudos atuais sobre Nadja tiveram muito a ganhar com a valorização do contato verbovisual, uma vez que o cenário crítico de desabono às ilustrações determinou a maneira como parte da crítica por muitas vezes analisou (ou desconsiderou) as imagens nessa obra de André Breton.

Ademais, Daniel Grojnowski, em "Le roman illustré par la photographie" (2005) enfatiza que a retirada de ilustrações empobreceria enormemente qualquer texto, tanto por seus efeitos estéticos quando em termos dos efeitos de sentidos. As ilustrações sempre marcam, em relação ao texto verbal, uma divergência e um apoio, uma tensão e um suporte. No caso das ilustrações fotográficas de que tratamos aqui, elas "operam pela intrusão de uma 'realidade' cujos poderes escapam às propriedades da linguagem"4 (GROJNOWSKI, [2005], tradução nossa). Assim, nas percepções desse crítico, "quando uma fotografia 'ilustra' uma narrativa, ela torna visível (lustrare: iluminar), isto é, perceptível e inteligível. Ela assegura a presença material do referente, ela faz nascer emoções e ela se dirige à compreensão"5 (GROJNOWSKI, [2005], tradução nossa).

Lembremos, por fim, que os tipos de relações geradas entre uma narrativa e a ilustração são tão numerosas quanto relevantes. As ilustrações podem, por exemplo, atuar como um elemento necessário para a compreensão do desenvolvimento do enredo, a exemplo dos casos analisados por Hans Lund, ou acrescentar ao texto uma "atmosfera" e um "cenário" que englobam e envolvem a narrativa, como acontece em Bruges-la-Morte (1892), de Georges Rodenbach. As imagens podem igualmente se confrontar com certas passagens do texto $\mathrm{e}$

Do original: opèrent par l'intrusion d'une « réalité » dont les pouvoirs échappent aux propriétés du langage. Do original: Lorsqu'une photographie «illustre» un récit, elle rend visible (lustrare : éclairer), c'est-à-dire perceptible et intelligible. Elle assure la présence matérielle du référent, elle fait naître des émotions et elle s'adresse à la compréhensio. 
gerar tensões produtivas. Em todos os casos, a relação texto-imagem interfere e exige do leitor uma recepção mais ativa, tendo em vista que "as imagens são informadas pela narrativa", são "habitadas pelos personagens, exprimindo seus pensamentos, seus desejos, suas emoções. Habitadas igualmente pelo ponto de vista, as reflexões do narrador"6 (GROJNOWSKI, [2005], tradução nossa).

Retomando o foco central desses estudos, lembramos que o livro Nadja foi lançado em 1928 e novamente publicado em 1963, em reedição revisada pelo autor. Na edição de 1963, o livro sofreu algumas alterações nas frases, recebeu do autor algumas notas de rodapé, um "Avant-dire (dépêche retardée) )", uma espécie de prefácio a essa edição, e modificações nas fotografias de sua composição.

Em seu curto "Avant-dire", o autor André Breton tece considerações sobre a sua publicação e chega a fazer explicações acerca de sua escolha por inserir as fotografias na constituição da obra. Sobre Nadja, o autor - considerando a inevitável chance de um resultado frustrado e dissonante de qualquer tentativa de se "retocar à distância a expressão de um estado emocional sem que se possa revivê-lo no presente" - defende a sua vontade de obter na reedição um efeito mais adequado "de termos e também de fluidez". Breton pondera que a tentativa de maior adequação seja, talvez, conveniente a essa obra de modo especial "em razão de um dos dois principais imperativos 'antiliterários' aos quais esta obra obedece" (BRETON, 2007, p. 19).

Obediente a dois imperativos "antiliterários" é o modo pois, como o autor vê a sua obra. Sem adentrarmos com profundidade às concepções ou aos objetivos de Breton ao anunciar um propósito "antiliterário", as inserções fotográficas são enumeradas como um desses princípios. Para o autor, em Nadja, são imperativos

a abundante ilustração fotográfica, que objetiva eliminar qualquer descrição - acusada de inanição no Manifesto do surrealismo -, o tom adotado para a narrativa, que se calca na observação médica, principalmente neuropsiquiátrica, [...], sem a mínima preocupação com o estilo (BRETON, 2007, p. 19-20, grifos nossos).

Do original: les images sont informées par le récit, [...] habitées par les personnages, exprimant leurs ensées, leurs désirs, leurs émotions. Habitées également par le point de vue, les réflexions du narrateurs Na tradução brasileira: “Antes de tudo (telegrama retido)" (BRETON, 2007, p. 19).
De antemão, pode-se notar que os seus dois imperativos antiliterários, "a ilustração fotográfica" e o "tom adotado", são assim considerados no sentido de combate às narrativas convencionais conhecidas por Breton, quais sejam os romances burgueses de tradição detalhista e "descritivista", de Balzac a Flaubert, passando por Stendhal e Zola, por exemplo. A aversão às descrições a que supostamente as fotografias são um "antídoto" - demonstra claramente a posição revolucionária do Surrealismo, antiliterária no que tange à literatura romanesca dos séculos XVIII e XIX, pautada no realismo literário, ou no que Ian Watt intitula com maestria como "Realismo formal" ${ }^{\text {. }}$

Acerca da abundância das descrições na literatura do século XIX, os ataques constantes no Manifesto do Surrealismo a esse procedimento literário são claros. Ambos os "imperativos antilitérios" são, a propósito, pautados nos objetivos e nas propostas presentes no Manifesto do Surrealismo. Certamente a eliminação da descrição defendida por Breton está relacionada à atitude antirrealista presente no Surrealismo, assim como acontece com a aparente descontinuidade e o caráter fragmentário presentes na narrativa que também podem ser incluídos nessa mesma recusa realista. A atitude realista, segundo Breton "tem um ar hostil a todo arrojo intelectual e moral" (BRETON, 2009, p. 223).

Portanto, o recurso fotográfico estaria, na explicação do autor, ligado ao sentimento de futilidade e de incapacidade da descrição literária que se vê no Manifesto:

E as descrições! Nada se compara ao nada delas; não passam de superposições de imagens de catálogos, de que o autor se serve cada vez mais à vontade, ele aproveita a ocasião para me passar seus cartões postais, procura fazer-me ficar de acordo com ele a respeito de lugares comuns (BRETON, 2009, p. 224)

E essa repulsa às descrições pode ser devidamente concebida como um princípio antiliterário, sem dúvida, e além disso antiestético, se observarmos

8 Referimo-nos aqui à ideia central defendida e explicitada por Ian Watt em $A$ ascensão do romance (1990). Grosso modo o Realismo formal seria para Watt a soma das técnicas literárias através das quais o romance imita a vida seguindo os procedimentos adotados pelo realismo filosófico, na tentativa de investigar e relatar a realidade. Notemos que, dentre as técnicas convencionais do Realismo formal, estariam a ambientac̃ão e colide. Not̃os que, dem como a individualizaç̃̃o das personogens com adoç̃o de nomes próprios habituais à época etc. 
que as descrições foram munidas na cultura ocidental "de uma finalidade perfeitamente reconhecida pela instituição literária", da "finalidade do belo" (BARTHES, 1972, p. 38), como demonstra Roland Barthes, em "O efeito do real" (1972). Nessa ótica, não todas, mas as descrições que atuam como um efeito de artificialidade, como uma ilusão referencial são, portanto, negadas, em uma recusa ao realismo literário, artificial na compreensão dos surrealistas.

O que se vê em Nadja, no entanto, não é a substituição ou a eliminação da atividade descritiva do texto literário. Em diversos casos, as fotografias utilizadas não comprovam a inanidade e a possibilidade de eliminação das descrições, uma vez que, se as descrições são reduzidas, não estão de nenhum modo ausentes no texto. A maioria das imagens não elimina as descrições e, em verdade, são complementares ao texto, ou ainda aparecem com comentários e são vinculadas a descrições. A título de exemplo, podemos invocar a fotografia à página 58, de um semicilindro irregular encontrado no Mercado das Pulgas de Saint-Ouen, antecedida de uma longa descrição detalhada de seus aspectos físicos ${ }^{9}$, o que corrobora a nossa compreensão contrária ao princípio fotográfico da supressão das descrições, tendo em vista que a pretensa economia descritiva parece estar anulada tanto neste quanto em outros exemplos. Nesses casos, as descrições, não substituídas pelas fotografias, ajudam, por sua vez, o leitor a chegar à percepção sensível de certos objetos surpreendentes.

Nesse sentido, acrescentamos que, em alguns casos, a descrição revela mais do que a imagem e aponta para características que o leitor/espectador não veria na fotografia. Como bem observa Pascaline Mourier-Casile (1994), em Nadja, d'André Breton, a fotografia da "luva de mulher", à página 61, não pode indicar por si só a materialidade do bronze que o texto intencionalmente o faz: "a dama planejou voltar para depositar sobre a mesa, no lugar onde tanto esperei que não deixasse a luva azul, outra luva, de bronze, que ela possuía e que depois vi em sua casa, igualmente uma luva de mulher" (BRETON, 2007, p. 59). Notemos, aliás, que esta informação não aparece sequer na legenda colocada sob a foto, "Igualmente uma luva de mulher", e que só caberá, portanto, àquele que lê a narrativa constatar essa informação.

Notemos como os detalhes que estão na imagem não são suprimidos na descrição no texto: "perversos, enfim, o sentido que entendo e amo, como, por exemplo, esta espécie de semicilindro branco, irregular envernizado, apresentando relevos e depressões sem significado para mim, com estrias verticais vermelhas e verdes, preciosamente acomodado num estojo, com uma divisa em língua italiana" (BRETON, 2007, p. 56).
Mourier-Casile considera, assim, que se trata de um exemplo de fotografia que "somente o texto [...] permite apreciar sua matéria e seu peso"10 (MOURIERCASILE, 1994, p. 137, tradução nossa), ao que complementamos ser essa uma indicação da relação de mútuas interferências entre texto e fotografia, porquanto estamos diante de um caso em que o texto fala o que a fotografia não pode dizer, em que o leitor pode compartilhar da sensação de contraste vivenciada pelo narrador apenas por meio do texto.

Somemos a isso que a luva de bronze, mais do que a sua matéria e o seu peso, metamorfoseia, de acordo com as interpretações de Patrick Née, em Lire Nadja (1993), "a leveza e o calor em uma massa fria exercendo seu peso", o que, como sabemos pela identificação de Lise Meyer ${ }^{11}$ como a "dama de luva", significa para Née que "nessa substituição [da "dama de luva" pela "luva de bronze"] se opera a "cristalização" do sentimento amoroso - pleno de ambivalência - por essa mulher"12 (NÉE, 1993, p. 66, tradução nossa). Por se configurar uma referência a uma mulher específica, o material, "bronze", não pode ser ignorado e, como a fotografia não pode evidenciar esse aspecto, compete à narrativa propor a pista ao leitor.

Esse fato evidencia mais uma vez a relação de troca e de complementariedade de sentidos (nem sempre literais, o que se pode ver no complexo processo de leitura da imagem da "luva de mulher") que verificamos em Nadja, ao contrário do que se poderia imaginar de ilustrações que duplicam o sentido do texto ou de fotografias que substituem em integralidade as descrições do texto. É o que reforça igualmente a percepção de Sophie Bastien, em "La Participation photographique dans les «Grandes proses» de Breton" (2009) de que, ainda que o texto e a imagem tratem do mesmo objeto, "não há uma relação tautológica entre os dois suportes". Diferente do que se vê na tradicional redundância, "Breton realiza uma complementariedade entre eles" ${ }^{13}$ (BASTIEN, 2009, p. 137, tradução nossa).

10 Do original: seul le texte [...] peut permettre d'apprécier la matière et le poids.

Mulher por quem Breton foi apaixonado e com quem ele manteve um relacionamento entre 1924 e 1927. Importante para seu processo produtivo, o autor manteve correspondência com ela durante a escrita de Nadja. Ver mais em Bonnet (1988) e Mourier-Casile (1994).

Do original: la légèreté vivante et chaude en une masse froide exerçant sa pesée" e "Dans cette substitution s'opère la «cristallisation» du sentiment amoureux - plein d'ambivalence - pour cette femme.

${ }_{13}$ Do original: il n'y a pas de relation tautologique entre les deux supports. [...] Breton réalise une complémentarité entre eux. 
Contudo nos é imperioso também sopesar que o tom narrativo dessa obra não pode ser considerado como neutro ou sem nenhuma preocupação com o estilo, o que igualmente nos faz duvidar que suas fotografias sejam imagens neutras, desprovidas de ponto de vista ou de intencionalidade, o que é completamente refutado, inclusive, por Paul Edwards, em Soleil noir (2008). Outrossim, aceitar um tom neutro, tanto em relação ao relato quanto à parte iconográfica da obra, seria contraditório dada a intenção confessada ao final da narrativa "de tomar uma imagem fotográfica do mesmo ângulo especial em que eu próprio as havia considerado" (BRETON, 2007, p. 138, grifo nosso).

Nesse tocante, Pascaline Mourier-Casile, que assim como outros críticos declarou que o que impressiona o leitor nas fotografias em Nadja é a "sua banalidade, sua neutralidade de 'cartão postal"'14 (MOURIER-CASILE, 1994, p. 140, tradução nossa), é duramente contestada por Paul Edwards, para quem, ao contrário do que afirma a crítica, isto é, que as fotografias em Nadja "não têm nada de especificamente surrealista"15 (MOURIER-CASILE, 1994, p. 140, tradução nossa), as imagens em Nadja põem em questão até mesmo a noção de representação do real. O mesmo vale para Daniel Grojnowski, que afirma, em Photographie et langage (2002), não encontrar nessa obra, "contrariamente ao que não para de repetir a tradição crítica" ${ }^{\prime 16}$ (GROJNOWSKI, 2002, p. 155, tradução nossa), uma única fotografia banal.

Para Paul Edwards, a lacuna deixada pelas análises de Mourier-Casile é precisamente a de "limitar o papel da fotografia àquele que lhe é sempre atribuído: o efeito de real” ${ }^{\prime 17}$ (EDWARS, 2008, p. 293, tradução nossa), ressalva primordial em nossas leituras. De acordo com esse crítico, não se pode aceitar essa perspectiva que vê "no livro uma narrativa 'ilustrada como uma obra científica, onde tudo o que se alega é verificável visualmente pelo leitor' (Henri Béhar), porque as ilustrações não se leem como pranchas do periódico La Nature"18 (EDWARS, 2008, p. 293, tradução nossa). Embora as análises de Edwards sejam conduzidas para uma leitura sobretudo psicanalítica das fotografias, o que não se pretende enfatizar aqui, essa desconfiança do "efeito

14 Do original: leur banalité, leur neutralité de «carte postale».

15 Do original: n'ont rien de spécifiquement sur-réaliste.

16 Do original: contrairement à ce que ne cesse de répéter la tradition critique

17 Do original: limiter le rôle de la photographie à celui qui lui est toujours dévolu: l'effet de réel.

18 Do original: dans le livre un récit «illustré comme un ouvrage scientifique, où tout ce qu'il allègue est vérifiable visuellement par le lecteur» (Henri Béhar), car les illustrations ne se lisent pas comme des planches du périodique La Nature. de real" e do "tom cientifico", viés pelo qual foram lidas correntemente as fotografias na obra de Breton, é uma cautela importante e que deve ser acolhida.

Parece-nos necessário, portanto, continuar as investigações sem desmerecer ou ignorar a declaração do autor em seu "Avant-dire" e as análises de diversos críticos. Devemos, entretanto, continuar analisando o modo como se dá a presença das fotografias, desconfiando da ilustração como duplicata e igualmente desta como eliminação das descrições, ou ainda apenas como "simples constatação" ou testemunha do real.

Dando sequência às análises e em consonância com o exposto, será importante verificar que as edições de 1928 e de 1963 contam com diferenças tanto na maneira de introdução das fotografias no livro quanto na quantidade de fotografias, passando de quarenta e quatro para quarenta e oito, bem como na escolha de algumas das imagens utilizadas.

Ademais as escolhas fotográficas estão em harmonia com o enredo, mas também com os pressupostos do Surrealismo e com as aspirações do autor. É evidente que grande parte das fotografias entrelaçam-se nas relações que as personagens estabelecem com os espaços físicos da narrativa e que podem ser erigidas ao seu valor testemunhal, como lugares em que os eventos aconteceram e cujas fotografias possam garantir e atestar a autenticidade e a veracidade dos fatos que se narram. Não há, entretanto, apenas essa maneira de "ler" tais fotografias. Acreditamos ser possível considerar, pelo seu elo com o texto, que de seu valor denotativo sobressaia-se um valor simbólico, conotativo.

Para Jean Arrouye, em "La photographie dans «Nadja»" (1983) a inserção da fotografia do Manoir d'Ango ${ }^{19}$ ou ainda a alteração desta e da estátua de Étienne Dolet na reedição de 1963, por exemplo, representações que poderiam ter sido apresentadas sob qualquer ângulo, qualquer enquadramento e qualquer luz, apontam para uma constatação primordial: "as fotografias de Nadja não são ilustrações [...], mas fazem parte integrante, atuante, do texto ${ }^{20 "}$ (ARROUYE, 1983, p. 123, tradução nossa). Diante das reflexões já suscitadas, também para Arrouye,

Propriedade em Varengeville-sur-Mer, na Normandia. Breton anuncia no próprio texto que teria se refugiado neste local para a escritura de Nadja, o que foi confirmado pelas pesquisas de Bonnet (1988).

Do original: "les photographies de Nadja ne sont pas des illustrations [..] mais font partie intégrante, actantielle, du texte. 
tudo "sugere que as imagens do livro têm outras funções além dessa, confessada, de substituir as descrições úteis ao relato ${ }^{21}$ " (ARROUYE, 1983, p. 126, tradução nossa).

Acrescenta-se, nessa linha de raciocínio, que esse crítico faz uma dupla confirmação acerca das imagens fotográficas em Nadja: por um lado, as fotografias não recobrem todas os lugares apresentados no texto e, assim, há tanto lugares quanto objetos evocados no texto para os quais não constam representações fotográficas; por outro, como já demonstrado, boa parte dos lugares e dos objetos das imagens fotográficas são igualmente descritos no texto. Todas as verificações obrigam-nos a concluir, definitivamente, que as imagens em Nadja não possuem a função mencionada pelo autor, de substituir e suprimir as descrições.

\section{Ilustração e complementariedade: a metáfora fotoliterária}

Nessa perspectiva, indaga-se, evidentemente, quais seriam as verdadeiras funções das fotografias na constituição da obra. Para Jean Arrouye (1983), o caráter objetal da imagem fotográfica sempre torna difícil (mas não impossível) a imposição e sobretudo o reconhecimento de um nível de significado e de pertinência simbólica além do retorno ao seu referente. Para além dessa retomada ao referente (ao qual a fotografia é forçosamente ligada) e investigando a possibilidade de leitura de um nível simbólico, encontramos a alternativa de ressignificação da imagem fotográfica, notadamente pelo contato com o texto literário. De acordo com Arrouye (1983), é exatamente isso que o texto literário promove em relação ao significado da imagem fotográfica: o texto possibilita uma leitura conotativa, isto é, a leitura da palavra literária converte e guia semanticamente a imagem e a valoriza simbolicamente.

Nesse sentido, embora cientes do percurso teórico e reflexivo de Roland Barthes e de suas mudanças no que concerne à fotografia, julgamos necessário perpassar as suas considerações sobre o denominado aspecto paradoxal da fotografia, verificado pelo teórico francês em "Mensagem fotográfica” (1990), cujas conclusões, apesar de não definitivas em seu pensamento, são valiosas para a compreensão do que se propõe aqui.

Do original: suggère que les images du livre ont d'autres fonctions que celle, avouée, de suppléer à des descriptions utiles au récit.
Nossa ressalva deve-se ao fato de sabermos que, ao se deparar com a teoria do índice fotográfico, a tentativa de Barthes verificada em seus dois primeiros textos dedicados à imagem ${ }^{22}$ - e à imagem fotográfica, particularmente - de inscrever a fotografia no âmbito semiológico e analisar o seu sistema de significações altera-se substancialmente em A câmara clara, publicado em 1980, ano de sua morte. Nessa obra, cujo repertório de conceitos e os princípios normativos são abandonados, Barthes desenvolve uma abordagem pautada nas sensações provocadas pela experiência daquele que vê a fotografia, única portanto, donde emerge o conceito de Punctum fotográfico, o que resulta em uma obra de alto teor poético e "decepcionante" aos que desejem encontrar a "chave" do código fotográfico, que permitiria decifrar todas as fotografias e a relação entre seus os significantes e os seus significados. Nessa obra fulcral, Roland Barthes erige, assim, para além da "perfeição analógica que, para o senso comum, define a fotografia" (BARTHES, 1990, p. 12) verificada no texto de 1961, o vínculo existencial e inerente da imagem e o seu referente, a aderência do referente, como a condição essencial da fotografia, seu traço distintivo.

Em "Mensagem fotográfica", por sua vez, a fotografia possui para Barthes o estatuto particular de "mensagem sem código" (BARTHES, 1990, p. 13), tendo em vista que "para passar do real à fotografia, não é absolutamente necessário dividir este real em unidades e transformar essas unidades em signos substancialmente diferentes do objeto cuja leitura propõem" (BARTHES, 1990, p. 12), conclusão já formulada a partir do estatuto indicial da fotografia, de "registro" do real, base das ideias elaboradas no texto de 1980. Essa percepção será retomada em 1964 em "A retórica da imagem" (1990), quando o teórico formulará que "na fotografia, pelo menos ao nível da mensagem literal, a relação entre os significantes e os significados não é de 'transformação', mas de 'registro', e a ausência de código reforça, evidentemente o mito do 'natural' fotográfico" (BARTHES 1990, p. 36).

Intrigado com esse aspecto fotográfico, Barthes observa que a fotografia se dá por "um análogo mecânico do real", o que resultaria em trazer "uma mensagem primeira que, de certo modo, preenche plenamente sua substância e não deixa lugar ao desenvolvimento da mensagem segunda" (BARTHES, 1990, p. 13). Imerso em reflexões sobre a fotografia de imprensa, o que não exclui a chance de um

Nos referimos aqui aos textos "Mensagem fotográfica" (p. 11-25), escrito em 1961, e "A retórica da imagem" (p. 27-43), de 1964, ambos publicados no livro O óbvio e o obtuso (1990). 
entendimento correlato em nossos estudos, e igualmente em consonância com as elucidações recuperadas no texto de 1964, Barthes, que houvera prenunciado uma impossibilidade de conotação na mensagem fotográfica, anuncia agora a sua hipótese de trabalho de que haja forte probabilidade "de que a mensagem fotográfica [...] seja, ela também, conotada" (BARTHES, 1990, p. 14).

Barthes propõe, assim, que a mensagem da fotografia pode ser conotada a partir de procedimentos específicos que ele enumera e esclarece. Reside nesse aspecto dual o que o teórico considera como "o paradoxo fotográfico", aquele da coexistência de duas mensagens na fotografia: uma sem código (o análogo) e outra com código (a "arte", a "escritura", a "retórica", o tratamento da imagem). Analogamente aos demais tipos de imagem, a fotografia, como mensagem icônica, possui uma mensagem literal e outra simbólica, embora uma mensagem denotada em estado puro, o "estado adâmico da imagem" (BARTHES, 1990, p. 35), seja algo utópico. No que concerne às diferenças da imagem fotográfica, contudo, segundo o semiótico, a denotação de um desenho, sempre marcado por seu estilo, seria menos pura do que a denotação fotográfica.

Para Roland Barthes (1990), porém, o paradoxo em si não reside apenas na dupla existência de uma mensagem denotada e outra conotada (caraterística que o autor sugere ser fatal a todas as comunicações de massa), mas sobretudo no fato de que a mensagem conotada se desenvolva a partir de uma mensagem sem código. Como gerar significados simbólicos para essa mensagem denotada, sem código? Barthes apresenta, assim, os procedimentos de conotação, ou seja, de codificação do análogo fotográfico, próprios do recurso fotográfico, como a trucagem, a pose, a sintaxe e a fotogenia, dentre outros.

O teórico apresenta, por fim, que, justamente pela relação com o texto, a imagem fotográfica também possa apontar para uma mensagem segunda, simbólica, conotativa. 0 texto, para Barthes, não irá jamais "dublar" a imagem, pois na passagem de uma estrutura a outra elaboram-se fatalmente significados segundos, mas o texto poderá amplificar um conjunto de conotações já incluídas na fotografia. Consoante o autor, "por vezes, também o texto produz (inventa) um significado inteiramente novo, que é, de certo modo, projetado retroativamente na imagem, a ponto de nela parecer denotado" (BARTHES, 1990, p. 21).

Em notável conclusão, Barthes reafirma a possibilidade de leitura das fotografias com um conteúdo simbólico, como iremos verificar a seguir nesses estudos. Para esse teórico, portanto, "ela [a fotografia] se desenvolve sob a forma de um paradoxo: aquele que faz de um objeto inerte uma linguagem e que transforma a incultura de uma arte 'mecânica' na mais social das instituições" (BARTHES, 1990, p. 25).

As noções acerca da polissemia fotográfica são iniciais nesse texto de Barthes e restritas em certa medida às fotografias de imprensa e às suas relações com a palavra. Essa questão é ampla e evidente nas teorias fotográficas e semióticas atuais. Nesse sentido, de acordo com as percepções de François Soulages, em Esthétique de la photographie (2017), a afirmação de Barthes em 1961 acerca da "mensagem sem código" teria feito a fotografia se fechar no reino da simplicidade e da não arte, ao passo que a polissemia seria uma característica de todas as artes. No entanto, podemos mesmo ver a abertura gradativa do pensamento de Barthes em um texto de 1977, no qual a fotografia é tomada como "a palavra, uma forma que quer de imediato dizer qualquer coisa"23 (apud SOULAGES, 2017, p. 236, tradução nossa).

0 grande mérito desses estudos barthesianos da imagem é precisamente o de, ao tratar da imagem pelo viés da retórica, dilatar a capacidade de uma análise igualmente sob a dupla perspectiva denotação-conotação sedimentada na percepção da linguagem verbal. Importa-nos salientar que, para Roland Barthes, por fim, o processo de conotação é constitutivo de toda imagem, mesmo das "aparentemente mais reais", como é o caso da fotografia. Martine Joly (2007), em Introdução à análise da imagem, evidencia que, para esse teórico, "uma imagem quer sempre dizer outra coisa para lá daquilo que ela representa em primeiro grau, isto é, ao nível da denotação" (JOLY, 2007, p. 96).

A partir dos estudos da retórica da imagem, na perspectiva de alargamento da retórica da linguagem verbal, parece-nos, pois, um atributo de todas as formas de expressão essa possibilidade de comunicar sentidos conotativos, o que desejamos enfatizar nas fotografias que compõem essa obra e que serão aqui analisadas também na sua qualidade de signo, cuja composição e as relações com as mensagens linguísticas que as rodeiam potencializam a amplitude de seus significados. Como bem observa Martine Joly, "a conotação não é inerente à imagem, mas é necessário considerá-la como constitutiva da significação pela imagem" (JOLY, 2007, p. 96).

É o que igualmente afirma sem ressalvas François Soulages, para quem trata-se de uma característica intrínseca da fotografia "ser potencialmente

23 Do original: le mot, une forme qui veut tout de suite dire quelque chose. 
rica de um número indefinido de sentidos"24 (SOULAGES, 2017, p. 237, tradução nossa), o que para nós significa levar em consideração os sentidos da leitura isolada das fotografias, denotativos e conotativos, bem como o surgimento de outros sentidos que brotam da relação com o texto.

Reconhecidas as propriedades conotativas da mensagem fotográfica e os procedimentos de inserção, de escolha e, salientemos, de preocupação acurada de André Breton quanto ao conteúdo fotográfico de sua obra, é necessário verificar de que modo o texto literário funciona como um index, designando e qualificando a maneira como as imagens deverão ser lidas e consideradas. Ainda para Arrouye (1983), há casos em que o texto designa o sentido das imagens e podemos acrescentar que as imagens devolvem ao texto significados novos. Portanto, em uma obra que alerta para a possibilidade de a vida requerer um movimento de decifração, e de o mundo ser dominado pelo "furor dos símbolos" (BRETON, 2007, p. 102), já está dada a orientação do modo como a imagem e o texto devem ser lidos: como criptogramas a serem decifrados.

Dessa profusão de ideias, defendemos ser possível ler as fotografias tanto em seu cerne denotativo, qual seja, apontar para a existência real dos lugares e monumentos de Paris, atestar a veracidade dos eventos narrados, tornar o relato coerente e plausível (visando a atingir o tom e não alterar o documento "tomado ao vivo", como adverte o autor); quanto em sua abertura semântica, a qual propõe significados simbólicos, passíveis de serem reconhecidos pelas trocas e cruzamentos com o texto. Sem, todavia, desvendar todos os criptogramas cifrados no texto e na imagem, mas para finalizar essa etapa de nosso percurso de reflexões, nos limitaremos a observar algumas fotografias para as quais lançaremos possibilidades de leitura. Nesse sentido, observemos, por fim, as fotografias da estátua de Étienne Dolet e a fotografia da placa "Les aubes".

A fotografia da estátua de Étienne Dolet foi alterada na reedição, pelo que tudo indica, buscando-se um "ângulo especial" que o autor pretendia, um ângulo que revelasse melhor a maneira como ele havia considerado as fotografias (conforme a queixa ao final do livro já mencionada). De acordo com as compreensões de Arrouye (1983) a nova fotografia (Figura 2) representa melhor o valor emotivo de Breton acerca da estátua. Arrouye salienta que, anteriormente (Figura 1) tomada em um "Plano de conjunto" (ou "Plano geral"),

24 Do original: être potentiellement riche d'un nombre indéfini de sens. via-se na edição de 1928 a estátua "liricamente instalada sobre o fundo de céu aberto, no espaço amplo da Place Maubert, onde passavam alguns pedestres" ${ }^{25}$. Na edição de 1963, porém, vemos que o enquadramento é mais fechado, em "Plano médio", e a fisionomia severa de Dolet ocupa a imagem, ao passo que "as coroas funerárias que se acumularam misteriosamente sobre o grupo do pedestal retêm a atenção"26 (ARROUYE, 1983, p. 135, tradução nossa), o que compreendemos estar em consonância com a sensação de "insuportável malestar" (BRETON, 2007, p. 29) causada no narrador.

Nessa esteira, é imprescindível notar que o enquadramento é mais do que um campo que dá a ver um aspecto da realidade, pois igualmente revela uma posição do operador em relação a ela. Assim, como um recorte parcial e motivado, o enquadramento atua diretamente em diversas funções possíveis de uma fotografia. Por essa escolha, para Arrouye, fica evidente que o autor utiliza muito conscientemente o efeito de moldura da fotografia ${ }^{27}$, ou seja, desse enquadramento em um espaço fechado que corta um aspecto particular do mundo, o que confere à estátua uma força simbólica.

E, de fato, o que se pode ver na comparação das duas fotografias é exatamente uma mudança de enquadramento, passando de uma vista mais geral da Place Maubert, em 1928 (Figura 1), para um plano mais fechado na estátua, em 1963 (Figura 2), cuja fotografia é tirada em "Contre-plongée", isto é, de baixo para cima, o que faz com que a ênfase recaia sobre as coroas funerárias colocadas no grupo de estátua junto do pedestal e exalta a estátua, sem dúvida o centro dos significados da imagem, o que outrora pode ter variado nas interpretações entre a estátua e a Place.
Do original : lyriquement installée, sur fond de ciel ouvert, dans l'espace large de la place Maubert où passaient quelques piétons.

${ }_{26}$ Do original: "les couronnes funéraires qui se sont mystérieusement accumulées sur le groupe du piédestal retiennent l'attention".

27 E de acordo com Arrouye esse mesmo procedimento de enquadramento fechado com efeitos análogos é encontrado em outras fotografias, como na da estátua de Becque e na da porta de "Camées durs". 




Fonte: Arquivos de André Breton ${ }^{28}$.



Resta-nos observar, então, que, se o novo enquadramento em plano fechado sobre a estátua é a escolha definitiva do autor e essa sugere a possibilidade de uma leitura simbólica, pergunta-se: que leitura seria essa?

Em primeiro lugar, acreditamos que esse plano de enquadramento explica melhor as sensações simultâneas de atração e de mal-estar vivenciadas pelo narrador. Isso acontece porque o célebre humanista, pensador e tradutor Étienne Dolet (1509-1546) certamente atraía o autor pelo pensamento livre, mas saber que aquela estátua de bronze fora ali erigida em $1889^{29}$ por ter sido o local de sua morte (agora claramente aludida pelas coroas de flores) por certo lhe causava um mal-estar insuportável. Étienne Dolet incorpora o símbolo

29 Hoje a estátua já não se encontra mais nessa praça parisiense, segundo pudemos constatar. 
da liberdade de pensamento, do espírito livre (igualmente personificado por Nadja) e, justamente por isso, foi queimado na Place Maubert em agosto de 1546.

Como pudemos ver, a imagem fechada na estátua revela o semblante sério do humanista, além de fazer surgir e dar ênfase às coroas funerárias. Talvez sejam esses os destaques que permitam ao leitor reconhecer ao mesmo tempo a atração (o espírito livre) e o mal-estar (da morte na fogueira, referidos duplamente pelo semblante e pelas coroas funerárias), aliás decorrentes um do outro, o que também anuncia a relação entre os espíritos livres e a morte (queimados, decapitados... como outros aludidos ao longo da narrativa, ou ainda, "perdendo a cabeça" metaforicamente, tal qual Nadja).

Acerca dessa escolha do enquadramento fotográfico, a pesquisadora Annateresa Fabris, em seu trabalho $O$ desafio do olhar: Fotografia e artes visuais no período das vanguardas históricas 2013), reconhece igualmente que,

vista de perto e ocupando o centro da composição, a imagem de Dolet impõe-se não só de maneira física, mas também psicológica, deixando compreender melhor os sentimentos ambivalente de Breton, invadido por sua presença muda mas eloquente, capaz de despertar uma grande tensão mental (FABRIS, 2013, p. 33).

Por outro lado, a estátua do humanista morto e as coroas funerárias destacadas nessa imagem não só entram em ressonância com o texto, duplicando essa sensação de mal-estar, como instauram a presença da morte no texto, morte essa que não estava anteriormente explícita, mas que reverbera agora na leitura do texto - morte, inclusive, presente em toda a narrativa e prenunciada desde a primeira fotografia, como poderemos ver na última parte deste trabalho.

O que podemos concluir dessas análises preliminares é que a obra literária aqui estudada comporta a fotografia em uma relação que gera equilíbrio significativo entre a palavra e a imagem, porquanto se torna patente a dupla e arranjada acomodação texto-imagem. Como se pode notar, a fotografia não é de modo algum um recurso tautológico em relação ao texto. Nessa perspectiva, nossas análises evidenciam e nos permitem defender a ideia de que haja em Nadja a dupla articulação fotoliterária que se configura como uma complementariedade entre o texto e a imagem, um gênero singular de "ilustração em complementariedade": trata-se para nós de um encadeamento texto-imagem que passaremos a designar, tomando de empréstimo um termo de outra área, como "ilustração em ressonância", por isso o seu modo de interação assemelhase ao de duas ondas que vibram juntas e assim aumentam as suas amplitudes.

E nesse contexto de interferência construtiva torna-se possível o desencadeamento do que preferiremos denominar "metáfora fotoliterária". Em outras palavras, trata-se de uma forma de interferência texto-imagem complementar e amplificadora que tem como uma de suas consequências essa transformação da fotografia em uma metáfora construída a partir do contato da fotografia com o texto literário em que está inserida e que devolve os significados simbólicos surgidos desse contato para a leitura do texto. Como veremos ainda em outro exemplo, a fotografia, metonímica por natureza, insere-se no texto, invade a narrativa e, na economia dessa obra, por essa interação texto-imagem, opera como uma metáfora fotoliterária.

Em consonância com nossas conclusões, podemos observar que Daniel Grojnowski (2002) reconhece existir uma relação muito particular em Nadja. Se em Bruges-la-Morte o leitor encontra uma "iconografia homogênea", constituída de imagens frequentemente intercambiáveis, cuja "repetição dos mesmos lugares e dos mesmos índices simbólicos perpetua o jogo de ecos"30 (GROJNOWSKI, 2002, 172, tradução nossa), em Nadja, por sua vez, para o crítico, o que se vê em contrapartida é o predomínio de "uma descontinuidade que perturba a comunhão entre as palavras e as imagens"31 (GROJNOWSKI, 2002, p. 173, tradução nossa). Importa-nos precisar que isso se dá porque as imagens que acompanham a flânerie são testemunhas de um cenário que prolonga as inquietudes e as reflexões dos dois passantes, mas, nessas imagens, os encadeamentos e as trocas, os detalhes imperceptíveis ou banais também "transformam a deambulação em uma busca de sentidos sempre reativada, regularmente reorientada"32 (GROJNOWSKI, 2002, p. 173, tradução nossa).

Retomando nossa ideia, o que podemos ver é que, em uma relação não redundante nem coerente, os movimentos de vai e vem, as transações encadeadas entre imagem e texto orientam, desorientam e reorientam as formas de leitura

Do original: répétition des mêmes lieux et des mêmes indices symboliques perpétue le jeu d'échos. Do original: une discontinuité qui trouble la communion entre les mots et le images.

Do original: transforment la déambulation en une quête du sens toujours réactivée, régulièrement réorientée. 
dessa obra fotoliterária, justamente porque texto e imagem têm um discurso e um sentido próprios que constantemente se contagiam e se interinfluenciam. Para Grojnowski, por fim, pela disposição das ilustrações de modo irregular e segundo uma lógica aleatória, essa obra "multiplica os acidentes de percurso" 33 (GROJNOWSKI, 2002, p. 173, tradução nossa) e revela o imprevisível. Em nossos termos, as interferências fotoliterárias geram a possibilidade de surgimento de sentidos novos e singulares, oferecidos ao leitor apenas a partir desse contato e desses movimentos que norteiam e desnorteiam e, assim, reorganizam a leitura da obra. E, em consonância com nosso ponto de vista, a notável formulação de Sophie Bastien nos permite bem concluir que "entre a imagem e o texto, um diálogo se instaura e um cruzamento de significações se tece [...] Embora cada mídia possua sua própria potencialidade, uma relação orgânica se enraíza entre as duas" ${ }^{\prime 34}$ (BASTIEN, 2009, p. 149, tradução nossa).

Acrescentamos ainda que esse vai e vem, esse cruzamento é igualmente físico e impacta na recepção dessa obra: as fotografias surgem no corpo do livro sem qualquer indicação direta no texto e causam ao mesmo tempo um efeito de surpresa e de suspensão. Isso porque se verifica uma arritmia na sequência e na divisão entre texto e imagem, dado que tanto há uma série consecutiva de cinco fotografias quanto há intervalos de quinze páginas sem nenhuma imagem. A presença das fotografias, inesperada e irregular quanto à frequência e à aparição, rompe com a linearidade da leitura, surpreende e desencadeia paradas no olhar do leitor, interrompendo o fluxo da leitura do texto e gerando outras formas de experiência de recepção da obra e outra maneira de retorno da leitura da imagem à leitura da palavra. Essa descontinuidade favorece uma sorte de irrupção e surpresa na leitura, porquanto o ato de ler é entrecortado de modo imprevisto, causando no leitor certa tensão e exigindo dele uma capacidade de adaptação do olhar e do intelecto.

Analisemos, finalmente, a última fotografia da obra (acrescida na edição de 1963). Tratava-se de uma placa indicativa azul, "Les aubes" (Figura 3), aparentemente desconexa e de pouco ou nenhum valor simbólico e que esconde parte de seu conteúdo: em primeiro lugar porque, de acordo com Maguerite Bonnet (1988) ${ }^{35}$, lia-se na placa "Sous les aubes", e em segundo

3 Do original: multiplie les accidents de parcours

34 Do original : Entre l'image et le texte, un dialogue s'instaure et un carrefour de significations se tisse [...] Bien que chaque média possède sa propre potentialité, un rapport organique s'enracine entre les deux. Referimo-nos aos comentários e estudos da obra constantes em BRETON, André. CEuvres complètes. porque acreditamos que essa imagem oculta outro significado profundo, que o texto certamente pede e aponta para ser decifrado.

Figura 3 - Edição de 1963

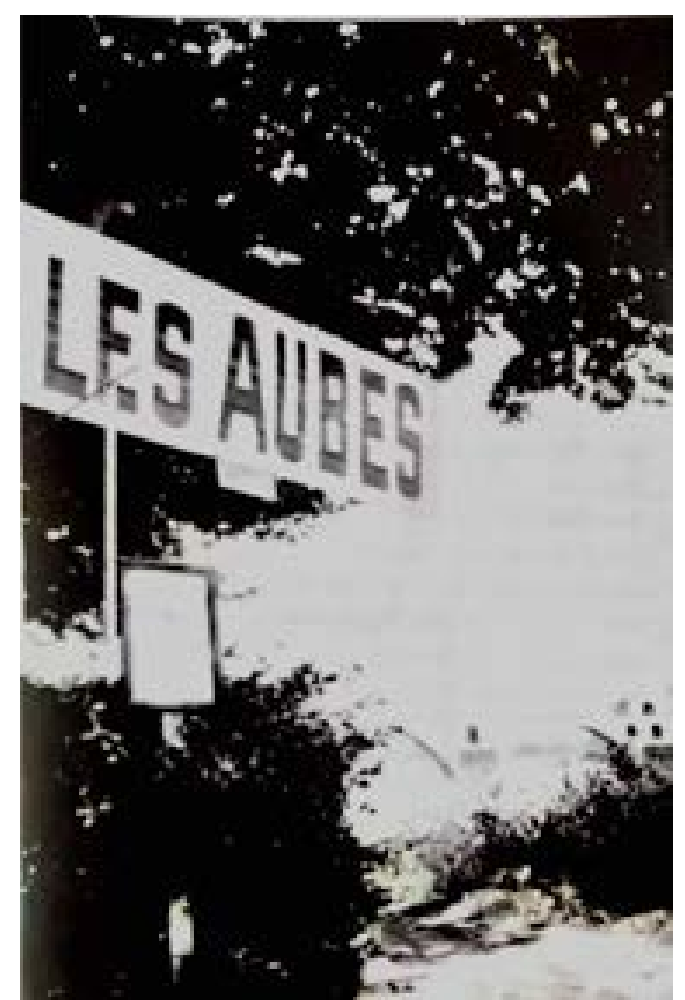

No contexto da narrativa, a placa surge após uma embaralhada alusão do narrador a um "esboço" dessa "paisagem mental, cujos limites me desencorajem, a despeito do seu espantoso prolongamento para os lados de Avignon". Dessa reflexão do narrador, segue-se que esse fora o lugar "onde uma velha ponte acabou caindo com o peso de uma canção infantil" e "onde uma intraível e

Vol. I. Paris: Gallimard, 1988 
maravilhosa mão apontou, não faz muito tempo, uma enorme placa indicativa azul-celeste, com estas palavras: LES AUBES" (BRETON, 2007, p. 141).

Como sabemos, a terceira parte da narrativa configura-se como uma espécie de epílogo, no qual se esconde - ao passo que se anuncia - um novo amor. A placa sugeriria, então, de modo complementar ao epílogo, o alvorecer daquele novo amor? Parece-nos uma hipótese plausível e validada pela lógica de interação texto-fotografia que merece ser investigada.

É possível encontrar informações bastante elucidativas nas explicações de Marguerite Bonnet ${ }^{36}$ : trata-se de uma parte do letreiro de um restaurante em Avignon, "Sous les aubes", onde Breton e Suzanne Muzard teriam almoçado em dezembro de 1927. Como se sabe, Suzanne Muzard foi amante de Breton enquanto ele era casado com Simone Kahn, pouco tempo depois do relacionamento com Nadja, e teria pedido ao escritor que deixasse sua esposa, o que se pode ver encoberto nessa parte do texto: o narrador passa a se dirigir a um "tu" enigmático, e o "tu" escondido no texto e na fotografia chega a dizer ao narrador "Tudo ou nada" (BRETON, 2007, p. 145), certamente uma referência a esse pedido, o que de fato Breton faz no outono de $1928^{37}$. Sobre a mão que se ergue e a placa indicativa, o leitor pode também vislumbrar seus vestígios: "Tu, que de tudo o que eu disse aqui só terás um pouco de chuva em tua mão, erguida para 'LES AUBES'” (BRETON, 2007, p. 143, grifo nosso). Tal como o narrador sugere, desse "tu" ficará em sua obra somente um rastro.

Se, por um lado, a placa esconde o nome do restaurante, por outro mostra a palavra que parece ser mais importante para a leitura do texto: aube, isto é, amanhecer, alvorecer, aurora, alvorada ${ }^{38}$.

Jean Arrouye, por sua vez, chega a considerar que essa fotografia se enquadre, a um só tempo, nas quatro categorias em que ele havia separado as quarenta e oito fotografias presentes em Nadja: essa fotografia mostra um objeto (1), ao passo que é também um documento (2), uma vez que é uma placa de um restaurante, e por isso mesmo é também a representação de um lugar (3), que em tudo tem igualmente o valor de um retrato (4) daquela que teria "apontado" a placa para Breton, daquela, inclusive, "que tudo leva ao romper do dia" (BRETON, 2007, p. 144, grifo nosso).

\footnotetext{
36 BONNET, 1988, p. 1559.
}

Como se pode ler nas cartas enviadas à Simone Kahn em 8 e 11 de outubro de 1928.

Lembramos igualmente que Aube é, aliás, o nome dado a sua filha (nascida em dezembro de 1935, de seu casamento com Jacqueline Lamba), a quem Breton se refere ostensivamente em L'Amour fou (1937).

Letrônica | Porto Alegre, v. 12, n. 3, jul.-set 2019: e33338
Nessa chave interpretativa, não é forçoso reconhecer o sentido simbólico da placa indicativa apresentada nessa ilustração em ressonância, surgido é claro da sua inserção no texto. É, portanto, irrevogável o caráter de metáfora fotoliterária dessa imagem: o "tu" e as referências à sua mão "apontam" para a leitura da placa como representação ligada ao surgimento daquela que é um novo amor, e a aurora inscrita na placa indicativa reverbera no texto, anunciando duplamente ao final do relato esse novo amor que se ergue, o que igualmente é reforçado pelo teor referencial da fotografia no que concerne ao contexto amoroso vivenciado pelo autor e pelo valor indicial da fotografia como rastro do real. Do mesmo modo que o texto permite entrever a nova amada, a fotografia também "apenas" a indica sem mostrá-la, deixando surgir um enigma. E a construção fotoliterária, no entanto, possibilita em sua interação que o leitor busque decifrar e, assim, possa vislumbrar no texto e na imagem o rosto desse novo amor que está raiando, que está ainda em estado de nascimento, que rompe o dia como uma grande aurora.

Nessa fotografia, mais uma vez em virtude da escolha do enquadramento, o seu valor documental, da indicação sinalizadora do restaurante em Avignon, atenua-se, dando lugar a esse significado fotoliterário. A fotografia converte-se, em suma, pelo recorte da imagem - que não deixa ver senão as letras LES AUBES - e pela relação com o texto, em símbolo desse novo amor que acaba de surgir.

Por tudo isso, parece-nos indiscutível que as imagens fotográficas se transformam, pelo contágio literário, em metáforas significativas. Nessa obra deve-se ler o texto e a imagem sempre em movimento de surpresa e de descoberta, tendo em vista que, também na leitura de Magali Nachtergael, em sua tese de doutorado Esthétique des mythologies individuelles: le dispositif photographique de Nadja à Sophie Calle (2008), as fotografias inseridas em Nadja são como documentos de uma realidade a ser desvendada e decifrada. Nas palavras da pesquisadora, "a fotografia aparece sobretudo como um instrumento de conhecimento e de revelação"39 (NACHTERGAEL, 2008, p. 85, tradução nossa), conforme pudemos verificar em nossas análises.

Do original: La photographie apparaît surtout comme un instrument de connaissance et de révélation. 


\section{REFERÊNCIAS}

ARROUYE, Jean. La photographie dans « Nadja ». Mélusine: Le Livre surréaliste, n. 4, p. 123$151,1983$.

BARTHES, Roland. 0 efeito do real. In: BARTHES, Roland et al. Literatura e Semiologia: Pesquisas Semiológicas. Petrópolis: Ed. Vozes, 1972. p. 35-44.

BARTHES, Roland. La chambre claire: notes sur la photographie. Paris: Éditions de l'Étoile: Gallimard, Le Seuil, 1980.

BARTHES, Roland. A câmara clara: notas sobre a fotografia. Tradução Julio Castañon Guimarães. São Paulo: Nova Fronteira, 1984.

BARTHES, Roland. O óbvio e o obtuso: ensaios críticos III. Tradução Léa Novaes. Rio de Janeiro: Nova Fronteira, 1990.

BASTIEN, Sophie. La Participation photographique dans les «Grandes proses» de Breton. In: VASSEVIÈRE, Maryse. La fabrique surréaliste. Actes du séminaire du Centre de Recherches sur le Surréalisme. Paris: Association pour l'étude du surréalisme et les auteurs, 2009. p. 129-149. Disponível em: http://melusine-surrealisme.fr/henribehar/wp/wp-content/ uploads/2014/10/5.-Fabrique_BAT.pdf. Acesso em: 12 mars. 2017.

BRETON, André. CEuvres complètes. Paris: Gallimard, 1988. v. 1.

BRETON, André. Nadja. Tradução Ivo Barroso. São Paulo: Cosac Naify, 2007.

BRETON, André. O manifesto do Surrealismo. In: TELES, Gilberto Mendonça. Vanguarda européia e modernismo brasileiro: apresentação dos principais poemas, manifestos, prefácios e conferências vanguardistas, de 1857 a 1972. 19. ed. Petrópolis: Vozes, 2009. p. 220-260.

BRETON, André. O Segundo Manifesto do surrealismo. In: TELES, Gilberto Mendonça. Vanguarda européia e modernismo brasileiro: apresentação dos principais poemas, manifestos, prefácios e conferências vanguardistas, de 1857 a 1972. 19. ed. Petrópolis: Vozes, 2009. p. 261-332.

BRETON, André. Lettres à Simone Kahn. Paris: Gallimard, 2016.

EDWARDS, Paul. Soleil noir: photographie et littérature des origines au surréalisme. Rennes : Presses Universitaires de Rennes, 2008.

FABRIS, Annateresa. $O$ desafio do olhar: fotografia e artes visuais no período das vanguardas históricas. São Paulo: Editora WMF: Martins Fontes, 2013. v. 2.
GROJNOWSKI, Daniel. Photographie et langage. Paris: José Corti, 2002.

GROJNOWSKI, Daniel. Le roman illustré par la photographie. In: LOUVEL, Liliane e SCEPI Henri. (dir.). Texte/Image: nouveaux problèmes. Rennes: Presses Universitaires de Rennes, 2005. p. 171-184. Disponível em formato online em: http://books.openedition.org/pur/30894. Acesso em: 09 déc. 2017. https://doi.org/10.4000/books.pur.30920

JOLY, Martine. Introdução à Análise da Imagem. Lisboa: Edições 70, 2007.

MONTIER, Jean-Pierre; LOUVEL, Liliane; MÉAUX, Danièle; ORTEL, Philippe (dir.). Littérature et photographie. Rennes: Presses Universitaires de Rennes, 2008.

MONTIER, Jean-Pierre (dir.). Transactions photolittéraires. Rennes: Presses Universitaires de Rennes, 2015 .

MONTIER, Jean-Pierre. La constellation métaphorique photolittéraire. Revue internationale de Photolittérature $\mathrm{n}^{\circ}$. 1, (En ligne), p. 1-11, oct. 2017. Disponível em: http://phlit.org/press/?post type $=$ articlerevue $\& \mathrm{p}=2877$. Acesso em: 05 mars. 2018

DINIZ, Thaïs Flores Nogueira; VIEIRA, André Soares (org.). Intermidialidade e estudos interartes desafios da arte contemporânea. Belo Horizonte: Rona Editora: FALE/UFMG, 2012. v. 2.

MOURIER-CASILE, Pascaline. Nadja d'André Breton. Paris: Gallimard, 1994.

NACHTERGAEL, Magali. Esthétique des mythologies individuelles: le dispositif photographique de Nadja à Sophie Calle. 2008. Tese (doutorado) - Université Paris-Diderot - Paris VII, Paris, 2008. Disponível em: https://tel.archives-ouvertes.fr/tel-00640863/document. Acesso em: 28 sept. 2017.

NÉE, Patrick. Lire Nadja. Paris : Dunod, 1993.

SOULAGES, François. Esthétique de la photographie. Paris: Armand Colin, 2017. 